\title{
Mechanical Spectroscopy of Ti-15Zr-based Alloys with Mo Addition
}

\author{
Diego Rafael Nespeque Correa ${ }^{a, c *}$, Luís Augusto Rocha ${ }^{a, b}$, Carlos Roberto Grandini ${ }^{a, b}$ \\ ${ }^{a}$ Instituto de Biomateriais, Tribocorrosão e Nanomedicina, Brazilian Branch - IBTN/BR, 17033-360, \\ Bauru, SP, Brazil \\ ${ }^{b}$ Laboratório de Anelasticidade e Biomateriais, Universidade Estadual Paulista - UNESP, 17033-360, \\ Bauru, SP, Brazil \\ 'Instituto Federal de Educação, Ciência e Tecnologia de São Paulo - IFSP, 18095-410, \\ Sorocaba, SP, Brazil
}

Received: January 17, 2017; Revised: October 16, 2017; Accepted: October 25, 2017

\begin{abstract}
In this paper, the effect of substitutional Mo amounts in internal friction and interstitial diffusion mechanisms was analyzed in Ti-15Zr-based alloys. Mechanical spectroscopy was obtained from room temperature up to $730 \mathrm{~K}$ with frequencies between $1 \mathrm{~Hz}$ and $40 \mathrm{~Hz}$. Internal friction spectra were composed by anelastic relaxation peaks in $\beta$-type alloys (metastable and stable), due to stress-induced ordering of oxygen and nitrogen interstitially in octahedral sites of the bcc crystalline structure. Peak decomposition analysis exhibited interactions between matrix-interstitial ( $\mathrm{Ti}-\mathrm{O}$ and Ti-N), substitutionalinterstitial ( $\mathrm{Zr}-\mathrm{O}$, Mo-O and Mo-N), and clusters (Ti-O-O and $\mathrm{Zr}-\mathrm{O}-\mathrm{O}$ ). The diffusion results showed that the introduction of Mo facilitates the diffusion of interstitial elements in the metallic matrix.
\end{abstract}

Keywords: Ti-Zr-Mo alloys, interstitial elements, internal friction, diffusion

\section{Introduction}

Mechanical spectroscopy is a useful tool for studying the interaction of gases in metals due to anelastic behavior of metallic materials. In metals, the anelastic relaxation effect is mainly produced by the movements of atoms such as oxygen, carbon, hydrogen, and nitrogen around interstitial sites (tetrahedral or octahedral symmetries) ${ }^{1}$. This effect can be induced by mechanical stress, producing a peak in the internal friction spectrum of the material $\left(\mathrm{Q}^{-1}\right)$. In an oscillatory system, the internal friction can be described by ${ }^{2}$ :

$$
Q^{-1}=\Delta\left(\frac{\omega \tau}{1+(\omega \tau)^{2}}\right)
$$

where $\omega$ is the oscillatory frequency and $\tau$ the relaxation time.

In the case of thermally-activated processes, the relaxation time assumes Arrhenius-type dependence with the temperature ${ }^{3}$ :

$$
\tau=\tau_{0} \exp \left(\frac{E}{k T}\right)
$$

with $\tau_{0}$ being the fundamental relaxation time, $\mathrm{E}$ the activation energy, and $\mathrm{k}$ the Boltzmann constant.

Therefore, the internal friction peak can be expressed as a function of the temperature ${ }^{4}$ :

$$
Q^{-1}=\frac{Q_{P}^{-1} T_{P}}{T} \sec h\left[\frac{E}{k}\left(\frac{1}{T_{P}}-\frac{1}{T}\right)\right]
$$

where $\mathrm{Q}_{\mathrm{P}}{ }^{-1}$ and $\mathrm{T}_{\mathrm{P}}$ are the maximum internal friction and temperature of the peak respectively.

Snoek's effect is a result of the stress-induced ordering of interstitial atoms around tetrahedral and octahedral sites in bcc crystalline structures, which is extensively studied in the literature ${ }^{5}$. In the case of octahedral sites of bcc structure, the diffusion coefficient of gases in metals can be expressed by ${ }^{3}$ :

$$
D=\frac{a}{36 \tau^{2}}
$$

where $\mathrm{a}$ is the lattice parameter of the metallic matrix.

As before, the diffusion coefficient assumes Arrheniustype dependence with the temperature in thermally-activated processes $^{3,4}$ :

$$
D=D_{0} \exp \left(-\frac{E}{k T}\right)
$$

where $\mathrm{D}_{0}$ is the diffusivity of the atom in the metallic matrix.

Diffusion coefficient data can be obtained from the internal friction measurements, based on the relation ${ }^{4}$ :

$$
\tau=\frac{1}{\omega}\left[\frac{Q_{P}^{-1} T_{P}}{Q^{-1} T} \pm \sqrt{\left(\frac{Q_{P}^{-1} T_{P}}{Q^{-1} T}\right)^{2}}+1\right]
$$

Internal friction measurements have been used to study the diffusion mechanisms of Ti-based alloys for use as biomaterials, such as $\mathrm{Ti}-\mathrm{Zr}{ }^{6}, \mathrm{Ti}-\mathrm{Mo}^{7}, \mathrm{Ti}^{-\mathrm{Ni}}{ }^{8}$, and $\mathrm{Ti}-\mathrm{Nb}{ }^{9}$ systems alloys. Ti-15Zr-based alloys with different amounts of Mo were developed to achieve favorable properties for 
biomedical materials, such as low Young's modulus and non-toxic composition ${ }^{10}$.

The purpose of this paper is to investigate the internal friction and diffusion mechanisms of interstitial elements (oxygen and nitrogen) in Ti-15Zr-xMo $(\mathrm{x}=0,5,10,15$ and $20 \mathrm{wt} \%$ ) alloys to verify the importance of alloying elements in influencing the anelastic behavior of the alloy.

\section{Materials and Methods}

Ti-15Zr-xMo ( $\mathrm{x}=0,5,10,15$ and $20 \mathrm{wt} \%)$ alloys were obtained from commercially pure metals by argon arc-melting. The ingots were submitted to homogenization treatment at $1273 \mathrm{~K}$ for $86.4 \mathrm{ks}$ with slow cooling, hot-rolling at 1273 $\mathrm{K}$ with air cooling and quenching at $1123 \mathrm{~K}$ for $7.2 \mathrm{ks}$ with water cooling. The measured chemical compositions were close to nominal values; the oxygen and nitrogen contents remained below $0.30 \mathrm{wt} \%$ and $0.03 \mathrm{wt} \%$ respectively ${ }^{10}$. Per previous microstructural analysis ${ }^{10}$, the alloys can be classified as $\alpha$ type (Ti-15Zr), $\alpha+\beta$ type (Ti-15Zr-5Mo), metastable $\beta$ type (Ti-15Zr-10Mo), and $\beta$ type (Ti-15Zr15Mo and Ti-15Zr-20Mo).

Mechanical spectroscopy was carried out with DMA50 equipment (Metravib) in the tensile mode. Quadrangular bars shape samples $(15 \times 5 \times 2 \mathrm{~mm})$ were used in the tests. The internal friction data were collected with a heating rate of $1 \mathrm{~K} / \mathrm{min}$, from room temperature up to $730 \mathrm{~K}$, and frequencies between $1 \mathrm{~Hz}$ and $40 \mathrm{~Hz}$. Peak decomposition was performed using the peak-fitting mode of Origin ${ }^{\circledR} 8.0$ software. Simulated peak decomposition was adjusted to match the experimental points (with a correlation factor of at least 0.9 ). The activation energy of metal-gas interactions was obtained from previous studies with binary system alloys ${ }^{3,4}$. Diffusion parameters were obtained from the internal friction data, following procedures detailed in the literature ${ }^{11}$, and using crystalline structural parameters obtained by XRD measurements in previous reports (Table 1$)^{10}$.

\section{Results and Discussion}

A comparison of the internal friction measurements as a function of the temperature (at $1 \mathrm{~Hz}$ ) for Ti-15Zr-Mo system alloys is presented in Fig. 1. The Ti-15Zr and Ti-15Zr-5Mo alloys did not present noticeable anelastic relaxation peaks due to the predominance of the hcp crystalline structure ( $\alpha$ phase) of the metallic matrix, the high-packed structure of which inhibits interstitial movements ${ }^{12}$. On the other hand Ti-15Zr-10Mo, Ti-15Zr-15Mo, and Ti-15Zr-20Mo alloys presented distinct anelastic relaxation peaks due to the bcc crystalline structure ( $\beta$ phase), which has a low-packed structure ${ }^{4,13}$. The peaks occurred at different temperature ranges, suggesting distinct processes of stress-induced ordering of interstitial elements ${ }^{5}$. Therefore, these measurements were subjected to peak decomposition analysis to identify the metal-gas interaction taking place in the alloys.

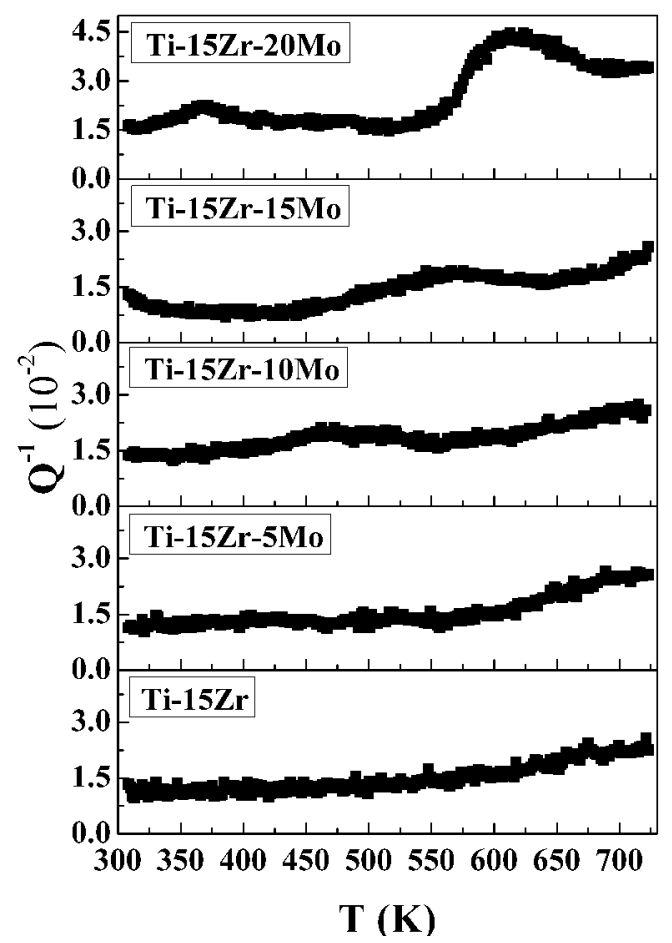

Figure 1. Internal friction as a function of temperature for the alloys of Ti-15Zr-Mo system.

The internal friction as a function of frequency and the anelastic peak decomposition between $400 \mathrm{~K}$ and $600 \mathrm{~K}$

Table 1. Crystalline structure of Ti-15Zr-Mo system alloys obtained by XRD (10).

\begin{tabular}{|c|c|c|}
\hline & Phase & Cell parameters \\
\hline Ti-15Zr & $\alpha^{\prime}$ & $\mathrm{a}_{\alpha^{\prime}}=0.286 \mathrm{~nm} ; \mathrm{c}_{\alpha^{\prime}}=0.467 \mathrm{~nm}$ \\
\hline Ti-15Zr-5Mo & $\alpha "+\beta$ & $\begin{array}{c}\mathrm{a}_{\alpha^{\prime \prime}}=0.299 \mathrm{~nm}, \mathrm{~b}_{\alpha^{\prime \prime}}=0.513 \mathrm{~nm}, \mathrm{c}_{\alpha^{\prime \prime}}=0.472 \\
\mathrm{nma}_{\beta}=0.330 \mathrm{~nm}\end{array}$ \\
\hline Ti-15Zr-10Mo & $\beta$ & $\mathrm{a}_{\beta}=0.330 \mathrm{~nm}$ \\
\hline Ti-15Zr-15Mo & $\beta$ & $\mathrm{a}_{\beta}=0.329 \mathrm{~nm}$ \\
\hline Ti-15Zr-20Mo & $\beta$ & $\mathrm{a}_{\beta}=0.328 \mathrm{~nm}$ \\
\hline
\end{tabular}


of the Ti-15Zr-10Mo alloy is shown in Fig. 2. The shift of the peak towards high temperatures, in correlation with the increase of frequency, indicates a thermally activated peak. The broad shape of the peak also suggests the presence of more than one kind of relaxation process ${ }^{14}$. Peak decomposition indicated the presence of Ti-O (dominant) and Ti-O-O processes, which are related to matrix-interstitial interactions of either oxygen atoms or clusters of oxygen atoms located in octahedral sites around the metallic matrix ${ }^{5}$. Table 2 presents the anelastic relaxation parameters such as frequency (f), peak temperature $\left(T_{P}\right)$, maximum internal friction $\left(Q_{P}^{-1}\right)$, and activation energy $(\mathrm{E})$ of each process.

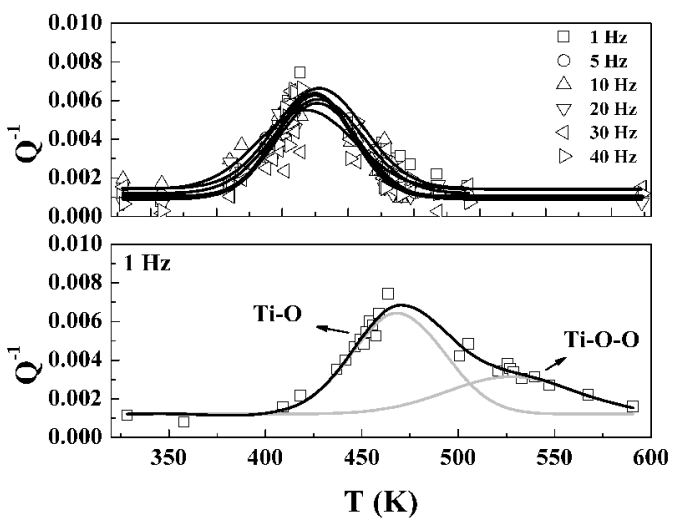

Figure 2. Peak decomposition of the Ti-15Zr-10Mo alloy.

Fig. 3 displays the internal friction as a function of frequency and the corresponding peak decomposition (between $450 \mathrm{~K}$ and $650 \mathrm{~K}$ ) of the Ti-15Zr-15Mo alloy. The alloy presented a broad peak which was clearly thermally activated. The peak positions of this alloy were slightly higher than those of Ti-15Zr-10Mo, suggesting a distinct relaxation process. The peak decomposition indicated a combination of $\mathrm{Zr}-\mathrm{O}$ (dominant) and $\mathrm{Zr}-\mathrm{O}-\mathrm{O}$ processes, related to substitutional-interstitial interactions among oxygen atoms and clusters around $\mathrm{Zr}$ atoms ${ }^{15,16}$. Table 2 presents the anelastic parameters of each process.

As exhibited in Fig. 1, the Ti-15Zr-20Mo alloy presented two distinct anelastic relaxation peaks, one between $325 \mathrm{~K}$ and $500 \mathrm{~K}$ (designated as low temperature), and the other between $500 \mathrm{~K}$ and $700 \mathrm{~K}$ (designated as high temperature). Internal friction as a function of frequency and the respective peak decompositions are shown in Fig. 4 and 5. At low temperatures (Fig. 4), the peak was comprised of Ti-O, Mo-O (dominant) and Mo-N processes, related to matrix-interstitial and substitutionalinterstitial interactions of oxygen and nitrogen atoms ${ }^{12}$. At high temperatures (Fig. 5), the peak was comprised of Ti-N, Zr-O (dominant) and $\mathrm{Zr}-\mathrm{O}-\mathrm{O}$ processes, related to matrix-interstitial and substitutional-interstitial interactions of oxygen and nitrogen atoms and clusters of oxygen around the $\mathrm{Zr}$ atoms of the alloy. It

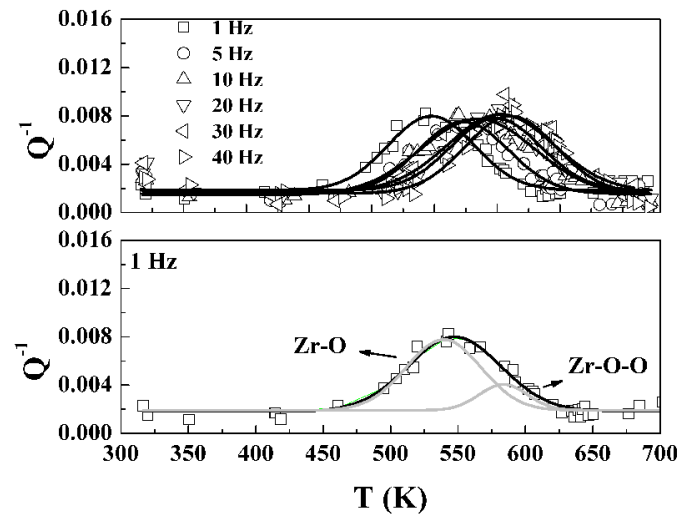

Figure 3. Peak decomposition of the Ti-15Zr-15Mo alloy.

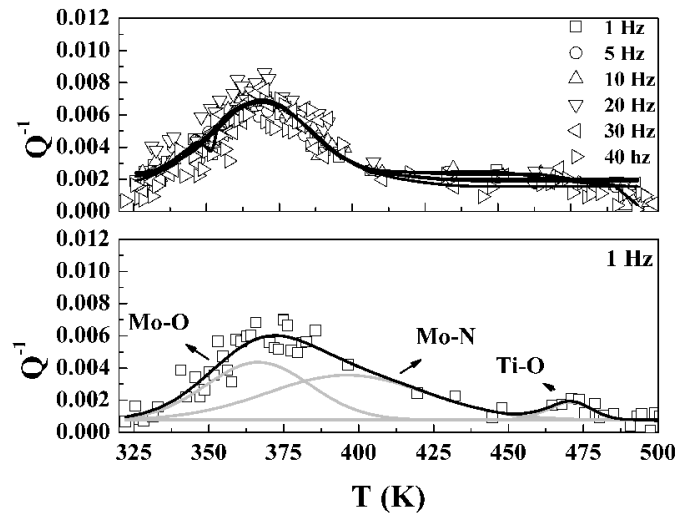

Figure 4. Peak decomposition of the Ti-15Zr-20Mo alloy at low temperatures.

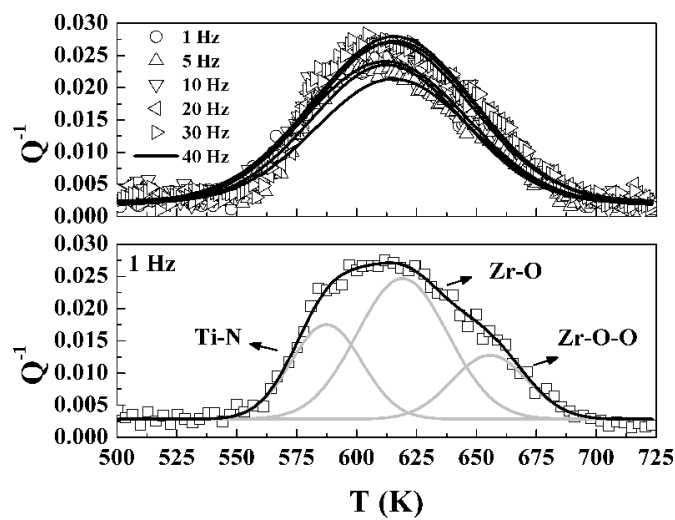

Figure 5. Peak decomposition of the Ti-15Zr-20Mo alloy at high temperatures.

can be observed that Mo-O and $\mathrm{Zr}-\mathrm{O}$ processes were dominant at low and high temperatures respectively, which indicates that the alloying elements directly affected the metal-gas interaction of the metallic matrix ${ }^{6}$. Anelastic relaxation parameters of each process can be seen in Table 2 . 
Table 2. Anelastic relaxation parameters for Ti-15Zr-Mo system alloys.

\begin{tabular}{|c|c|c|c|c|c|c|c|c|}
\hline \multicolumn{2}{|c|}{ Alloy } & \multicolumn{3}{|c|}{ Ti-15Zr-10Mo } & \multicolumn{2}{|c|}{ Ti-15Zr-15Mo } & \multicolumn{2}{|c|}{ Ti-15Zr-20Mo } \\
\hline Process & $\mathrm{E}(\mathrm{eV})$ & $\mathbf{f}(\mathrm{Hz})$ & $\mathbf{T}_{\mathrm{P}}(\mathbf{K})$ & $\mathbf{Q}_{\mathrm{P}}^{-1}$ & $\mathbf{T}_{\mathrm{P}}(\mathbf{K})$ & $\mathbf{Q}_{\mathrm{P}}^{-1}$ & $\mathbf{T}_{\mathrm{P}}(\mathbf{K})$ & $Q_{P}^{-1}$ \\
\hline \multirow{6}{*}{ Ti-O } & \multirow{6}{*}{1.23} & 1 & 421 & 0.0058 & - & - & 454 & 0.0021 \\
\hline & & 5 & 453 & 0.0051 & - & - & 464 & 0.0019 \\
\hline & & 10 & 457 & 0.0043 & - & - & 471 & 0.0017 \\
\hline & & 20 & 459 & 0.0038 & - & - & 485 & 0.0015 \\
\hline & & 30 & 460 & 0.0032 & - & - & 487 & 0.0012 \\
\hline & & 40 & 473 & 0.0027 & - & - & 488 & 0.0011 \\
\hline \multirow{6}{*}{ Ti-O-O } & \multirow{6}{*}{1.30} & 1 & 462 & 0.0044 & - & - & - & - \\
\hline & & 5 & 475 & 0.0029 & - & - & - & - \\
\hline & & 10 & 478 & 0.0018 & - & - & - & - \\
\hline & & 20 & 480 & 0.0016 & - & - & - & - \\
\hline & & 30 & 481 & 0.0011 & - & - & - & - \\
\hline & & 40 & 482 & 0.0007 & - & - & - & - \\
\hline \multirow{6}{*}{ Zr-O } & \multirow{6}{*}{1.50} & 1 & - & - & 537 & 0.0066 & 603 & 0.0270 \\
\hline & & 5 & - & - & 539 & 0.0064 & 604 & 0.0262 \\
\hline & & 10 & - & - & 549 & 0.0064 & 607 & 0.0250 \\
\hline & & 20 & - & - & 563 & 0.0063 & 614 & 0.0225 \\
\hline & & 30 & - & - & 580 & 0.0059 & 619 & 0.0223 \\
\hline & & 40 & - & - & 593 & 0.0057 & 621 & 0.0218 \\
\hline \multirow{6}{*}{ Zr-O-O } & \multirow{6}{*}{1.56} & 1 & - & - & 580 & 0.0022 & 645 & 0.0112 \\
\hline & & 5 & - & - & 583 & 0.0022 & 647 & 0.0111 \\
\hline & & 10 & - & - & 611 & 0.0017 & 655 & 0.0102 \\
\hline & & 20 & - & - & 614 & 0.0016 & 656 & 0.0101 \\
\hline & & 30 & - & - & 645 & 0.0014 & 657 & 0.0100 \\
\hline & & 40 & - & - & 654 & 0.0011 & 659 & 0.0099 \\
\hline \multirow{6}{*}{ Мo-O } & \multirow{6}{*}{1.09} & 1 & - & - & - & - & 356 & 0.0036 \\
\hline & & 5 & - & - & - & - & 360 & 0.0027 \\
\hline & & 10 & - & - & - & - & 367 & 0.0019 \\
\hline & & 20 & - & - & - & - & 367 & 0.0017 \\
\hline & & 30 & - & - & - & - & 368 & 0.0016 \\
\hline & & 40 & - & - & - & - & 370 & 0.0013 \\
\hline \multirow{6}{*}{ Mo-N } & \multirow{6}{*}{1.23} & 1 & - & - & - & - & 356 & 0.0058 \\
\hline & & 5 & - & - & - & - & 369 & 0.0042 \\
\hline & & 10 & - & - & - & - & 370 & 0.0030 \\
\hline & & 20 & - & - & - & - & 371 & 0.0028 \\
\hline & & 30 & - & - & - & - & 372 & 0.0023 \\
\hline & & 40 & - & - & - & - & 396 & 0.0019 \\
\hline \multirow{6}{*}{ Ti-N } & \multirow{6}{*}{1.61} & 1 & - & - & - & - & 573 & 0.0195 \\
\hline & & 5 & - & - & - & - & 576 & 0.0190 \\
\hline & & 10 & - & - & - & - & 578 & 0.0191 \\
\hline & & 20 & - & - & - & - & 580 & 0.0159 \\
\hline & & 30 & - & - & - & - & 581 & 0.0146 \\
\hline & & 40 & - & - & - & - & 587 & 0.0147 \\
\hline
\end{tabular}

The anelastic relaxation processes obtained by peak decompositions indicated that the bcc structure was fundamental for promoting stress-induced ordering of interstitial elements in the alloy. The decompositions also showed that the $\mathrm{Zr}$ and Mo atoms interacted with single atoms or clusters of oxygen and nitrogen. Nogueira et al. ${ }^{7}$ identified the anelastic relaxation processes of Ti-O, Ti-N, Mo-O, and Mo-N in the Ti-10Mo alloy. Similarly, Vicente et al. ${ }^{16}$ studied the internal friction of Ti-5Zr and
Ti-10Zr alloys, which were composed of the Ti-O, Ti$\mathrm{O}-\mathrm{O}, \mathrm{Zr}-\mathrm{O}$ and $\mathrm{Zr}-\mathrm{O}-\mathrm{O}$ anelastic processes. This shows that that the alloy composition plays an important role in metal-gas interaction throughout the matrix-interstitial and substitutional-interstitial processes. In this study, we observed that both alloying elements contributed to the metal-gas interaction. The calculated anelastic relaxation parameters (Table 2) remained close to distinct studies in the literature ${ }^{3,4}$. 
Table 3. Diffusion parameters for Ti-15Zr-Mo alloys system.

\begin{tabular}{ccccccc}
\hline \multirow{2}{*}{ Alloy } & \multicolumn{3}{c}{ Nitrogen } & \multicolumn{3}{c}{ Oxygen } \\
\cline { 2 - 7 } & $\mathbf{E ~}(\mathbf{e V})$ & $\mathbf{D}_{\mathbf{0}}\left(\mathbf{m}^{2} / \mathbf{s}\right)$ & $\boldsymbol{\tau}(\mathbf{s})$ & $\mathbf{E}(\mathbf{e V})$ & $\mathbf{D}_{\mathbf{0}}\left(\mathbf{m}^{2} / \mathbf{s}\right)$ & $\boldsymbol{\tau}(\mathbf{s})$ \\
\hline Ti-15Zr-20Mo & 0.21 & $7.7210^{-15}$ & $3.8910^{-7}$ & 1.63 & $3.4110^{-12}$ & $8.8110^{-10}$ \\
Ti-15Zr-15Mo & - & - & - & 1.31 & $3.5110^{-14}$ & $8.6110^{-8}$ \\
Ti-15Zr-10Mo & - & - & - & 1.63 & $4.9710^{-17}$ & $6.0710^{-5}$ \\
\hline
\end{tabular}

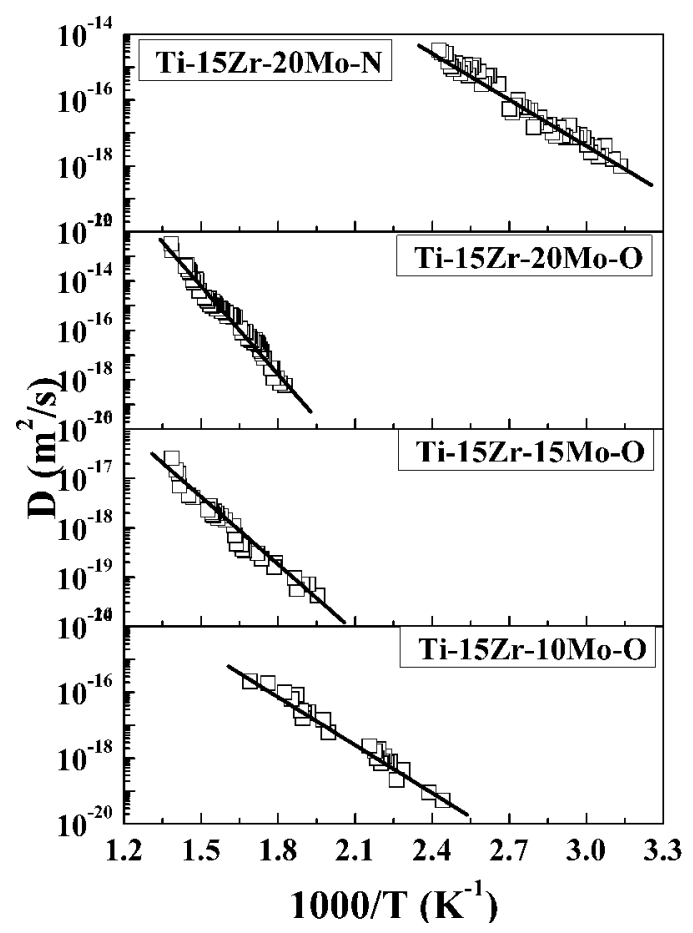

Figure 6. Diffusion coefficient as a function of temperature for the alloys of Ti-15Zr-Mo system.

Based on the internal friction data, the anelastic relaxation processes were analyzed in terms of their interstitial diffusion mechanisms. Fig. 6 presents the Arrhenius curves produced by oxygen and nitrogen diffusion. Ti-15Zr-5Mo and Ti-15Zr10 Mo exhibited diffusion related only to oxygen, while Ti-15Zr-20Mo presented diffusion related to nitrogen and oxygen. The respective diffusion parameters are exhibited in Table 3, which lists the activation energy of the whole relaxation process $(\mathrm{E})$, diffusivity $\left(\mathrm{D}_{0}\right)$, and relaxation time $(\tau)$. It is possible to observe a lower diffusivity value of nitrogen than oxygen, possibly due to the difference in atomic radius $(0.055 \mathrm{~nm} \text { for nitrogen and } 0.060 \mathrm{~nm} \text { for oxygen })^{17}$, ${ }^{18}$. It is also possible to observe a dependent relationship between oxygen diffusivity and chemical composition. When Mo was added to the, there was a gradual increase of the diffusivity and a decrease in the relaxation time, indicating easy mobility (jumps) of interstitial atoms in the metallic matrix sites ${ }^{5,18}$. This heightened mobility may be a result of the low atomic radius of the Mo that allows it to increase the size of hole spaces in the metallic matrix ${ }^{10}$. Vicente and Grandini ${ }^{6}$ studied the diffusion of interstitials in Ti-15Zr$\mathrm{xMo}(\mathrm{x}=5,10$, and $15 \mathrm{wt} \%)$, obtaining diffusivity values around $10^{-8} \mathrm{~m}^{2} / \mathrm{s}$. However, the oxygen content of these alloys remained lower than $0.05 \mathrm{wt} \%$. Martins Jr. et al. ${ }^{19}$ obtained diffusivity values around $10^{-14} \mathrm{~m}^{2} / \mathrm{s}$ for oxygen and nitrogen in the Ti-15Mo alloy, with the values dependent to the interstitial concentrations. Therefore, this study supports the assumption that the interstitial diffusivity and relaxation time depend on the interstitial and substitutional contents of the alloy ${ }^{11,20}$.

\section{Conclusion}

The internal friction behavior of Ti-15Zr-based alloys with different contents of Mo was analyzed, having the relaxation processes and diffusional parameters evaluated in terms of alloy's composition. The anelastic relaxation processes occurred mainly in $\beta$-type alloys (bcc crystalline structure). Anelastic peaks were decomposed in processes involving the alloying elements, with individual atoms or clusters of oxygen and nitrogen, in matrix-interstitial and substitutional-interstitial mechanisms. The diffusion coefficients were dependent on the alloys' chemical compositions; having the amount of Mo facilitated the diffusion of interstitial elements as its atomic radius was smaller than those of Ti and $\mathrm{Zr}$. The results obtained in this study contribute to the future understanding of the interaction mechanisms of gases in metals.

\section{Acknowledgements}

The authors acknowledge the Brazilian agencies CNPq (grant \#207417/2015-6) and FAPESP (grant \#2015/00851-6 and \#2010/20440-7) for their financial support.

\section{References}

1. Menard KP. Dynamic Mechanical Analysis - A Pratical Introduction. Boca Raton: CRC Press; 1999. 205 p.

2. Nowick AS, Berry BS. Anelastic Relaxation in Crystalline Solids. New York: Academic Press; 1972.

3. Blanter MS, Golovin IS, Neuhaüser H, Sinning HR. Internal Friction in Metallic Materials. Berlin: Springer; 2007. 522 p.

4. Puškár A. Internal Friction of Materials. Cambridge: Cambridge International Science Publishing; 2001. 
5. Weller M. The Snoek relaxation in bcc metals-From steel wire to meteorites. Materials Science and Engineering: $A$. 2006;442(1-2):21-30.

6. Vicente FB, Grandini CR. Diffusion of Oxygen in Ti-15Mo-xZr Alloys Studied by Anelastic Spectroscopy. Defect and Diffusion Forum. 2014;354:159-165.

7. Nogueira RA, Grandini CR, Claro APRA. Oxygen diffusion in Ti-10Mo alloys measured by mechanical spectroscopy. Journal of Materials Science. 2008;43(17):5977-5981.

8. Kustov S, Salas D, Cesari E, Santamarta R, Mari D, Van Humbeeck J. Structural anelasticity, elasticity and broken ergodicity in Ni-Ti shape memory alloys. Acta Materialia. 2014;73:275-286.

9. Silva Jr PS, Florêncio O, Stefanini TF, Grandini CR. Medidas dos coeficientes de difusão do oxigênio e nitrogênio em nióbio através de relaxações anelásticas. Revista Brasileira de Aplicações de Vácuo. 2004;23(1):20-23.

10. Correa DRN. Efeito de elementos substitucionais e intersticiais nas propriedades mecânicas e na biocompatibilidade de ligas do sistema Ti-15Zr-xMo. [Thesis]. Bauru: Universidade Estadual Paulista Júlio de Mesquita Filho; 2015. 132 f.

11. Grandini CR, de Almeida LH, Nogueira RA, Niemeyer TC. Diffusion of Interstitial Elements in Ti Alloys Used as Biomaterials. Defect and Diffusion Forum. 2009;283-286:30-37.

12. Chaves JM, Florêncio O, Silva PS Jr, Marques PW, Afonso $\mathrm{CR}$. Influence of phase transformations on dynamical elastic modulus and anelasticity of beta Ti-Nb-Fe alloys for biomedical applications. Journal of the Mechanical Behavior of Biomedical Materials. 2015;46:184-196.
13. Usategui L, Nó ML, Mayer S, Clemens H, San Juan J. Internal friction and atomic relaxation processes in an intermetallic Mo-rich Ti-44Al-7Mo $\left(\gamma+\beta_{\circ}\right)$ model alloy. Materials Science and Engineering: A. 2017;700:495-502.

14. Yin F, Yu L, Ping D. Modeling and control of the high damping behavior in Ti-Nb-O alloys. Materials Science and Engineering. A. 2009;521-522:372-375.

15. Almeida LH, Grandini CR, Caram R. Anelastic spectroscopy in a Ti alloy used as biomaterial. Materials Science and Engineering: A. 2009;521-522:59-62.

16. Vicente FB. Influência do oxigênio nas propriedades anelásticas e biocompatibilidade de ligas Ti-5Zre Ti-10Zr. [Dissertation]. Bauru: Universidade Estadual Paulista Júlio de Mesquita Filho; 2010. $115 \mathrm{f}$.

17. Lide DR. CRC Handbook of Chemistry and Physics. Boca Raton: CRC Press; 2005. 2661 p.

18. Balogh Z, Schmitz G. Diffusion in Metals and Alloys A2. In: Laughlin D, Hono K, ed. Physical Metallurgy. $5^{\text {th }}$ ed. Oxford: Elsevier; 2014. p. 387-559.

19. Martins Júnior JRS, Nogueira RA, de Araújo RO, Grandini CR. Diffusion of Oxygen and Nitrogen in the Ti-15Mo Alloy Used for Biomedical Applications. Defect and Diffusion Forum. 2012;326-328:696-701.

20. Chaves JM, Florêncio O, Silva PS Jr, Marques PWB, Schneider SG. Anelastic relaxation associated to phase transformations and interstitial atoms in the Ti-35Nb-7Zr alloy. Journal of Alloys and Compounds. 2014;616:420-425. 